\title{
Trend Analysis on Road Traffic Accident in Nigeria
}

\author{
Muritala Abdulkabir 1, ", Raji Surajudeen Tunde², Udokang Anietie Edem² \\ ${ }^{1}$ Statistics Department, University of Ilorin, Ilorin, Nigeria \\ ${ }^{2}$ Mathematics and Statistics Department, Federal Polytechnic, Offa, Kwara State, Nigeria
}

\section{Email address:}

kaybeedydx@gmail.com (M. Abdulkabir)

\section{To cite this article:}

Muritala Abdulkabir, Raji Surajudeen Tunde, Udokang Anietie Edem. Trend Analysis on Road Traffic Accident in Nigeria. Science Innovation. Vol. 3, No. 5, 2015, pp. 52-57. doi: 10.11648/j.si.20150305.12

\begin{abstract}
This paper center on Trend Analysis on Road Traffic Accident in Nigeria, it is aim to determine the direction of trend of number of accident in Ibadan, Oyo state, Nigeria using time series analysis for prediction and decision making. From the analysis it was discovered that there will be an increase in the number of accident occurring in the future.
\end{abstract}

Keywords: Time Plot, Trend Analysis, Forecasting, Road Traffic Accident

\section{Introduction}

The rates of motor vehicle accident have been systematically extensively investigated in many parts of the world. Motor vehicles accidents are caused by unforeseen circumstances usually producing unpleasant and unexpected consequences.

Motor vehicles accident has been described as having the worst side effect on man in the modern society. The opposite of accident is safety, and it is concerned with the taking of all necessary precautions against the occurrence of accident.

Also motor vehicles accident could be seen as event or hazards that contribute a lot of fear to communities as it is an undesirable and frequently occurring event with economic and human losses caused by uncontrolled disturbance in the interaction of component in a system. Many researchers have written on the causes and control of motor vehicle accident on the highways notable among whom are professor Wole Soyinka, Professor Eghusa Osagwa, Eyiola Oni, Solomon A.A, A.A. Omidiji and others but due to continue development in the world today, road traffic injuries pose a major public health challenges that requires concerted efforts to reduce through effective and sustainable method of preventions. An estimated 1.3 million people are killed through road accident annually around the world and as many as 50 million suffers injuries.

The world health organization (WHO) believes that this figure will increase to 1.9 million if concrete action is not taking by the end of 2020, especially in developing country such as Nigeria (Road Safety Nigeria and Nigeria tribune march $\left.13^{\text {th }} 2009\right)$.
In Nigeria, the federal road safety commission (FRSC) is the government agency with statutory responsibilities for road safety administration prior to the establishment of FRSC in 1988 by formed head of state, general Ibrahim Babanginda there was no concrete and sustainable policy action to address the carnage on our road. Earlier attempt in this direction were limited to discrete and isolated attempt by individuals.

Shell petroleum tried and they failed in 1960-1965, the Nigerian army started the first training of its men o road safety campaign in 19772. It was officially created in 1994 which was then called Nigeria road safety commission (FRSC) by General Ibrahim Babanginda.

The impact of the commission was not however sustained, with the continue dangerous trend of road traffic accident in Nigeria. In February 1988, the federal government established the (FRSC) through decree No. 45 of the 1988 as amended by decree 35 of 1992 which is referred to in the status book as the FRSC ACT cap 41 laws of the federation of Nigeria

Many scholars and researchers have carried out studies or researches and have also wrote books, project etc on the statistical analysis on rate of motor vehicle accident on Nigeria road over a period of time. These people have used different statistical tool such as time-series analysis, chisquare analysis, correlation coefficient analysis, multiple regression co-efficient analysis etc to analyze their data.

From Thomson (1991) made us know that the rate of accident on our roads can be reduce if the road users such as drivers, passengers and pedestrians are properly oriented and educate on the important of safety precaution on the roads. 
According to his suggestion, he made us know that the best way to analyze any data on road accident is to use regression analysis in order to forecast for the future occurrences of such accident.

And Oloyede (2010) made use of multiple correlation coefficient to analyze her data and she concluded that the government should improve on the measures against motor vehicle accident, then the total number of accident and adverse socio-economic effect would be greatly place to move forward confidently into an advanced or development country.

Falohun (2001) made use of chi-square to analyze his data. From his findings he conclude that there will be decreased in the rate of accident on the road that will be cause by environment hazard if the government and the federal road safety commission should maintain and enforce law on the traffic offenders.

Jekayinta (2007) carried out in a research title "time series analysis of road accident in Osun state said in order to improve the work of FRSC there should be an emergency line for the commission in which they will call in case of accidents.

Then Berstrom and Bjortig (1991) made use of time series to analyze their data and conclude that the road accident can be reduces if government and federal road safety corps should maintain the following recommendation.

1. The FRSC should ensure strict enforcement law on any traffic offenders.

2. Government should improves other form of transportation particularly rail transport in order to reduce the traffic volume on the roads.

3. They should orientate or educate the drivers and other road users on the important of the safety on the highways.

Mazharul (2012). Presented a profile of recent growth trends of motorization and the pattern of related road traffic accidents in Oman. The study is likely to establish the baseline facts about the transportation system and RTA problems in Oman. Data for the study come from royal oman police (ROP) record and world health organization (WHO) report for international comparison. On the average there are 230 vehicles per 1, 000 populations in Oman, and between 2000 and 2009, it has increased by $26 \%$. Private car and shared taxi services are the major modes of personal transport I Oman. In 2009, there were 2.67 accidents per 1, 000 population or 9.59 accidents per 1, 000 registered vehicles in Oman. RTA shows declining trends during the study period.

Rongjie, Mohamed (2013) provided a systematic approach to investigate the different characteristic of week-day and weekend crashes. A multivariate Poisson model and correlated random effects Poisson model were estimated; model goodness of-fits have been compared though DIC values. In addition to the safety performance functions, a disaggregate crash time propensity model was calibrated with Bayesian logistic regression model. It was concluded that weekday crashes are more probable to happen during congested sections, while the weekend crashes mostly occurs under free flow conditions.

Chorr, Samer (2013) stated that the objective of this study is to develop a safety propensity index (SPI) for both signalized and unsignalized intersections. Through the use of a structural equation modeling (SEM) approach safety is quantified in terms of multiple endogenous variables and related to various dimensions of exogenous variables. The singular valued SPI allows for identification of relationship between models. the data provided by the highway safety information system (HSIS) for the California transportation network was utilized for analysis. In total 22,422 collisions at unsignalized intersections and 20,215 collisions at signalized intersections (occurring between 2006 and 2010) were considered in the final models. The main benefits of the approach and the subsequent development of and SPIO are 1. The identification of pertinent variables that effect safety at both intersection types, (2) the identification of similarities and differences as both types of intersections through model comparison, and (3) the of safety in the form of an index scuh that a ranking system can be developed. If further developed, the adopted methodology may assit in safety related decision making and policy analysis.

Kahled (2004) presented a conceptualization of indicators. The paper moves on to develop a number of statistical models that can be used in the prediction of the expected number of accidents, injuries, fatalities and causalities on the rural roads in Egypt. Time series data of traffic and accidents, over a 10 years period for the considered roads, is utilized in the calibration of these predictive models. Several functional forms are explored and tested in the calibration process. Before proceeding to the development of these model three ANOVA statistical tests are conducted to establish whether there are any significant differences in the data used for models' calibration as a result of differences among the considered five roads.

Humblet \& Lagasse (1999) stated that road traffic injuries are major public health problem. In this study, they choose years of potential life lost (YPLL) to analyze the trends during the period 1974-1994 and the relative impact of the traffic injuries death on total mortality and on total avoidable mortality in Belgium. We analyzed the geographical trends over a 20-years period at the district level. The YPLL ageadjusted rates were analyzed for usuccessive 5-year periods: 1974-1978, 1980-1984, 1985-1989, 1990-1994 and the ratios of YPLL rates were used to describe changes between 1974 and 1994 at district level. The YPLL rates decrease for 'all causes mortality', 'total avoidable causes' and 'road traffic injuries'. This trend can be observed during the four periods of 5 years. A slowing down of the decrease of the YPLL rates of road traffic injures, both for men and women is observed; $11.7 \%$ between periods 2 and 1 , and only 3\% between periods 4 and 3 for men (16.2 and 7.5\% for women). The geographical analysis shows marked differences between districts. Even though a favorable trend is observed for the traffic injuries deaths in Belgium it is important to highlight the important slowing down of this trend during the most 
recent years. It is also necessary to underline the importance of geographical disparities in the distribution of YPLL rates within the entire populations.

The aims and objectives of this research work are as to determine the trend of road traffic accident during the period under review and to develop a predictive model for future occurrences of numbers of motor accident.

\section{Methodology}

\subsection{Time Series Analysis}

One of the main objectives of statistics is to forecast the future levels of economic activities by studying the behavior of the data in the past. The most important techniques of making references about the future on the basis of what has happened in the past is the analysis of time series. Which may be define as a set of observations taking at specified times, usually at equal intervals.

\subsection{Components of a Time Series}

In analyzing time series we may take the observed composite series as a whole for study or study one by one respectively the components in their own right.

The components are:

1. Secular trends

2. Seasonal trends

3. Cyclical variations

4. Random or irregular variations

\subsection{Mathematical Model of Time Series}

There are two types of model in time series which are generally accepted as good approximations to the time relationship among the components of the observed data. They are the additive and multiplicative models, and are the most commonly assumed relationship between time series and its elements.

1. Additive model: this assumes that the value of composite series is the sum of the four components, that id $\mathrm{Y}=\mathrm{T}+\mathrm{S}+\mathrm{C}+\mathrm{I}$

Where Y- original

$\mathrm{T}$ - values of secular trend

$\mathrm{S}$ - value of seasonal component

C - value of irregular component

I - value of irregular component

2. Multiplicative model assumes that the value of composite series is the product of four component values, that is $\mathrm{Y}=\mathrm{TxSxCxI}$. Generally, the multiplicative model has been considered the standard conventional model for analysis of time series.

\subsection{Measurement of Trend}

The following are the four methods which are generally used for the study and measurement of the trend component in a time series.

1. The freehand method
2. Moving average method

3. Method of least squares

In this research work, the method of least-squares is used to estimate the trend value of time series by determine the equation for the best time of fit and also use it to determine whether there will be an increase or decrease in the observed data by predicting for the future occurrence

The least square method uses the equation of a straight line $y=a+b x$ which is also the equation for the best time of fit. Line of regression is the line which gives the best estimation of one variables for any given value of the other variable. The term best fit is interpreted in accordance with the principle of least squares which consist in minimizing the sum of the squares of the residuals or error of estimates, i.e. the derivations between the given observed values of the variables and their corresponding estimated values as given by the line of best fit.

For any given point $\mathrm{P} 1(\mathrm{x} 2, \mathrm{y} 1)$ in the scatter diagram, the error of estimate or residual as given by the line of best fit is $\mathrm{P} . \mathrm{H}$ now the $\mathrm{x}$-coordinate of $\mathrm{Hi}$ is same as that of $\mathrm{Pi}(\mathrm{xi})$ and since Hi (xi) lies on the line the y-coordinate of Hi, i.e. Hi M given by $(\mathrm{a}+\mathrm{bxi})$. Hence the error of estimate for $\mathrm{Pi}$ is given by $\mathrm{PiHi}=\mathrm{PiM}-\mathrm{Hi} \mathrm{M}$

$$
\mathrm{y}_{\mathrm{i}}=\mathrm{a}+\mathrm{bx}
$$

We can obtain the of a straight line $y=a+b x$ by solving the normal equations which will enable us to find the value of a and $b$ where.

Derivation of line of least square of $\mathrm{Y}$ on $\mathrm{X}$

Let $(\mathrm{Xi}, \mathrm{yi}(\mathrm{x} 2, \mathrm{y} 2) \ldots$. Be $\mathrm{n}$ pairs of observation on the two variable $\mathrm{x}$ and $\mathrm{y}$ under study.

Let $\mathrm{y}=\mathrm{a}+\mathrm{bx}$ be the line of regression (best fit) of $\mathrm{y}$ on $\mathrm{x}$.

$$
\begin{aligned}
& y=\beta_{0}+\beta_{1} X_{1}+\ell_{i j} \\
& \ell_{i j}=y-b_{0}-b_{1} x_{1} \\
& \sum_{i=1}^{n} e_{i j}{ }^{2}=\sum\left(y-b_{0}-b_{1} x_{1}\right)^{2} \\
& \text { differentiate partially first with respect to } b_{0} \\
& 2 \sum\left(y-b_{0}-b_{1} x_{1}\right)=0 \\
& \sum_{i=1}^{n} y-n b_{0}-b_{i} \sum_{i=1}^{n} x_{1}=0 \\
& b_{0}=\frac{\sum_{i=1}^{n} y-b \sum_{i=1}^{n} x_{1}}{n}-\cdots-\cdots(1) \\
& b_{0}=\bar{y}-b_{1} \bar{x} \\
& \text { differentiate partially sec ond with respect to } b_{1} \\
& 2 \sum_{i=1}^{n} x_{1}\left(y-b_{0}-b_{1}\right)=0 \\
& \begin{array}{l}
\sum_{i=1}^{n} x_{1} y_{1}-b_{0} \sum_{i=1}^{n} x_{1}-b_{1} \sum_{i=1}^{n} x_{i}^{2}=0 . \\
\text { substitute for } b_{0} \text { in equation }
\end{array} \\
& \sum x_{i} y_{i}-\frac{\sum x \sum y-b_{1}\left(\sum x\right)}{n}-b_{1} \sum x_{i}^{2}=0 \\
& b_{1}=\frac{n \sum x y-\sum x \sum y}{n \sum x^{2}-\left(\sum x\right)^{2}} \\
& \hat{b}=\frac{n \sum t x-\sum t \sum x}{n \sum t^{2}-\left(\sum t\right)^{2}} \\
& \text { also } \\
& \hat{a}=\bar{y}-b \bar{x}
\end{aligned}
$$




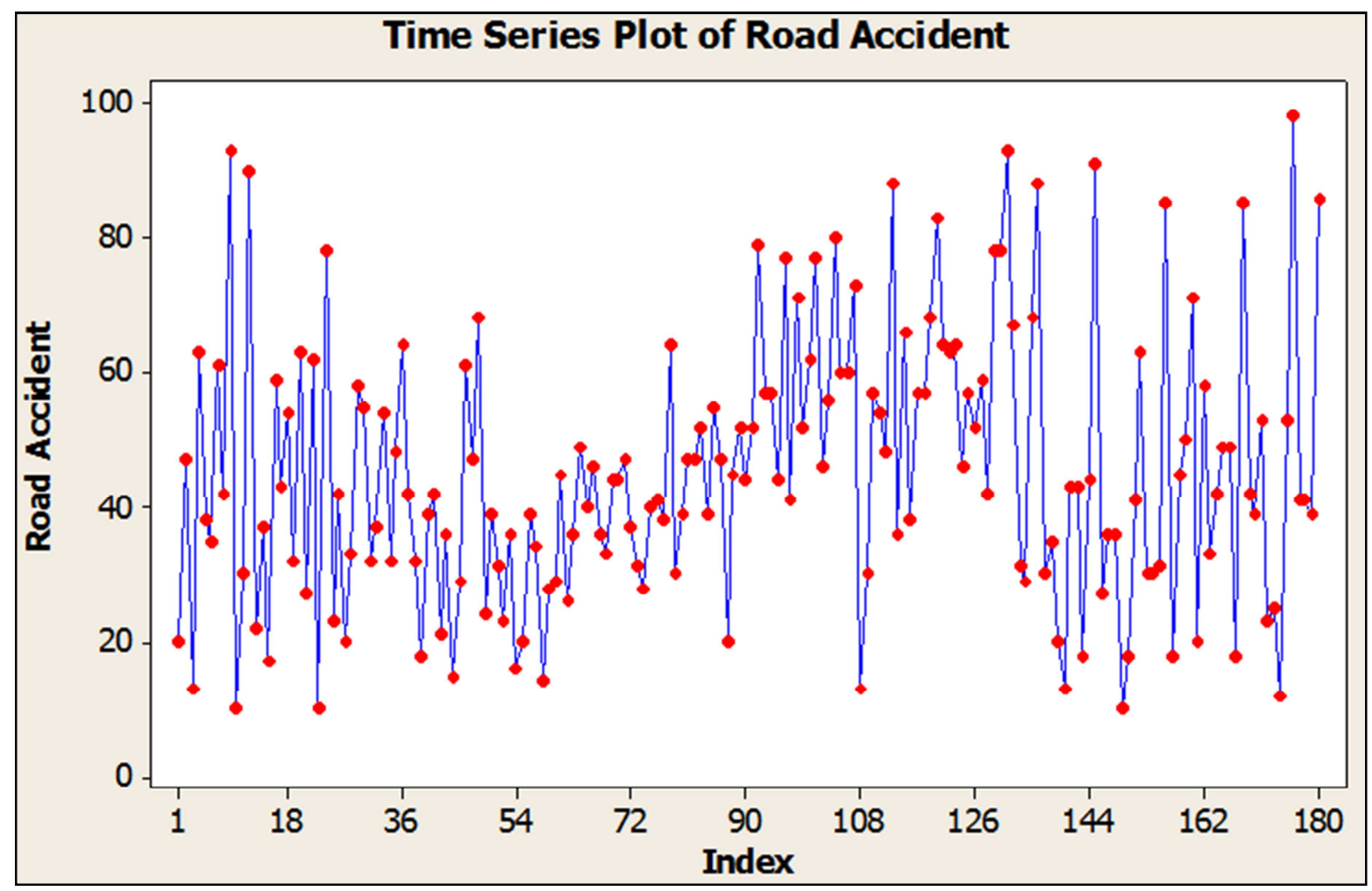

Figure 1. Time plot on road accident.

Trend analysis

Fitted Trend Equation

$\mathrm{Yt}=39.70+0.0599 * \mathrm{t}$

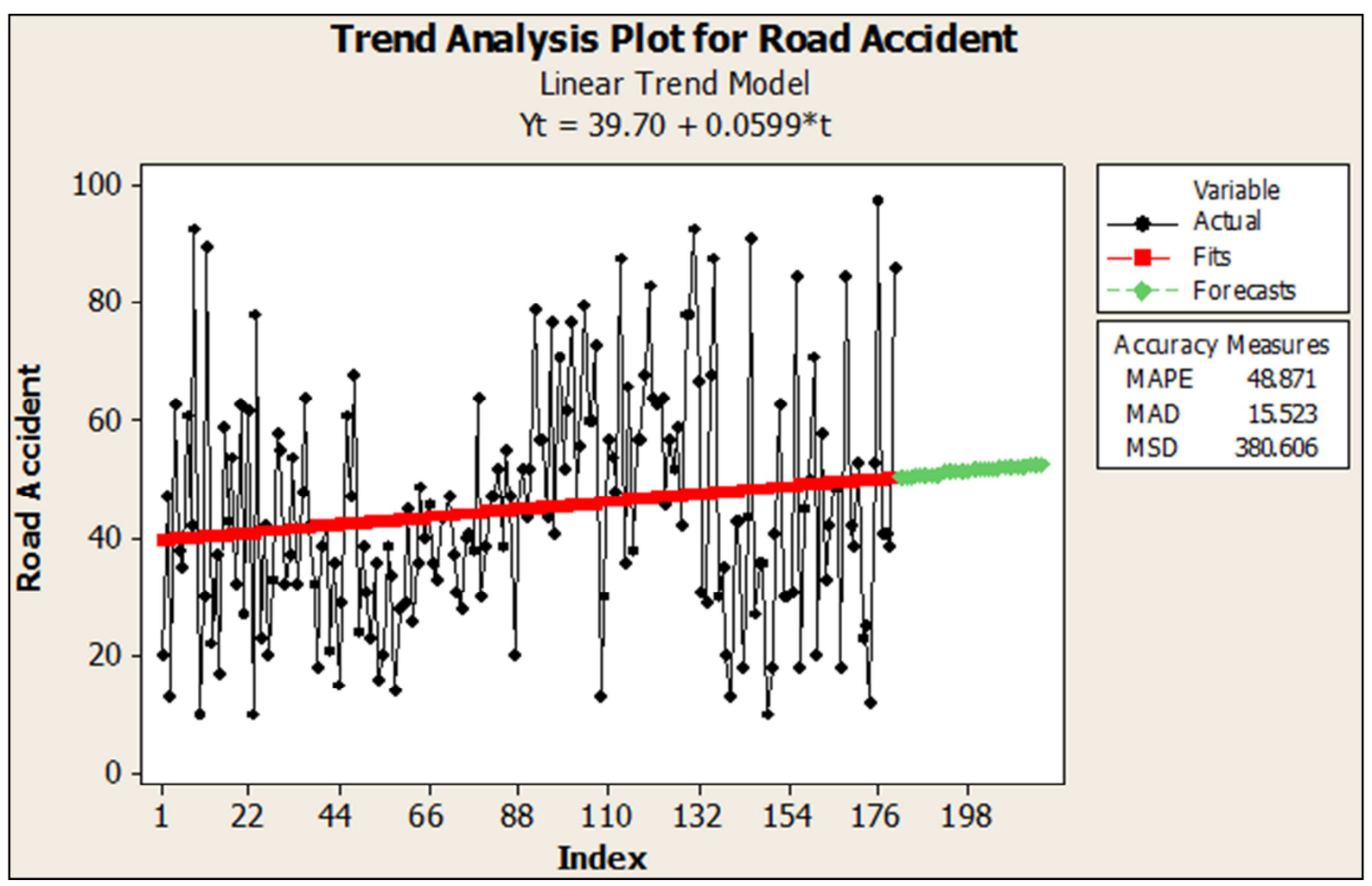

Figure 2. Trend Analysis Plot for Road Accident. 


\subsection{Analysis}

Forecasting for the 2014-2016

Period Forecast

$181 \quad 50.5372$

$182 \quad 50.5971$

$183 \quad 50.6570$

$184 \quad 50.7169$

$185 \quad 50.7768$

$186 \quad 50.8367$

$187 \quad 50.8966$

$188 \quad 50.9565$

$189 \quad 51.0164$

$190 \quad 51.0763$

$191 \quad 51.1362$

$192 \quad 51.1961$

$193 \quad 51.2560$

$194 \quad 51.3159$

$195 \quad 51.3758$

$196 \quad 51.4357$

$197 \quad 51.4956$

$198 \quad 51.5555$

$199 \quad 51.6154$

$200 \quad 51.6753$

$201 \quad 51.7352$

$202 \quad 51.7951$

$203 \quad 51.8550$

$204 \quad 51.9148$

$205 \quad 51.9747$

$206 \quad 52.0346$

$207 \quad 52.0945$

$208 \quad 52.1544$

$209 \quad 52.2143$

$210 \quad 52.2742$

$211 \quad 52.3341$

$212 \quad 52.3940$

$213 \quad 52.4539$

$214 \quad 52.5138$

$215 \quad 52.5737$

$216 \quad 52.6336$

\section{Discussion of Result}

Fifteen (15) years data were extracted from the document of Federal Road Safety Corps (FRSC) on number of accidents, the data were obtained on monthly basis. Time series analysis were used to determine the trend line and also used to fit the linear trend model, the model was used to predict for future occurrence on accident and it was discovered that there will be an increase in the number of accident occurring in the future.

\section{Conclusions}

The primary aim of this research is to determine the trend of road traffic accident base on the analysis used in the project work, it was discovered that there will be an increase in the number of accident occurring in the future.

\section{Recommendations}

As a result of conclusion reached, the following recommendation was made in order to reduce road accident

1. Government should provide good roads and making the highway's safer for motorist and other road users.

2. There should be an enlighten program for road users in other not to drive and ride in a reckless manner and abide by the rules and regulations governing transportation.

3. In order to improve the work of federal road safety corps (FRSC) there should be an emergency line for the commission in which they will call in case of accident

4. The pedestrians should make use of the zebra crossing or the pedestrian bridge when crossing the highway.

5. The drivers must ensure that their vehicles are properly fitted with good brakes, clean wind screen, seat belt, inflated tyres etc. when getting up for a journey

\section{References}

[1] Adepoju A, Azeez O. I, Okeniyi O. M, And Raji S. T (2004); An introduction to Business Statistics (Third Edition) Publishing by Rajah Dynamic Printer Ilorin, Kwara state.

[2] Adekunle J. A. (2010), Road traffic Accident Deaths and Socio-Economic Development in Nigeria.

[3] Adewole T. A, Odetunde O. J, Ibrahim B. G And Ijaiya G. T (2000); Introduction to Social Science Research Methods.

[4] Ahmed, M. Abde-Aly, M. Yur. R, (2012); A Bayesian Updating Research Approach for Real Time Safety Evaluation using data. Journal of transportation research board. 2280, 6067.

[5] Babalola J. B. (2012); The Basic Statistics for Business Management, Science and Technology (Revised Edition).

[6] FRSC, Sector Command, Ibadan Oyo state (2013), Policy Research and Administrative Department.

[7] Johansen S. 1995. "Likelihood-based inference in cointegrated vector-auto regressions. In Advanced Texts in Econometrics, Oxford: Oxford University Press.

[8] Kaled A. Abass (2004). Traffic Safety Assessment and Development of Predictive Models for Accidents on Rural Roads in Egypt.

[9] Olabode K. J (2013). Introduction to research methodology.

[10] Pesaran, M. H. \& Shin Y. 1995. An Autoregressive Distributed Lag Modelling approach to cointegration analysis. DAE Working Paper No. 9514, Department of Applied Economics, University of Cambridge.

[11] Pesaran, M. H., Shin, Y. \& Smith, R. J. 1996. Testing for the existence of a long run relationship. DAE Working Paper No. 9622, Department of Applied Economics, University of Cambridge. 
[12] Royal Omen Police (ROP) 2009, Traffic Statistics Sultanate of Omen Directorate General of Traffic, ROP. 